\title{
Educational Model of Four Legged Robot
}

\author{
Alexander Gmiterko, Michal Kelemen*, Ivan Virgala and Lubica Miková \\ Technical University of Košice, Faculty of Mechanical Engineering, Letná 9, 04200 Košice
}

\begin{abstract}
Alexander Gmiterko, prof. Ing. CS. He received M.S. degree in electrical engineering from Slovak Technical university of Bratislava, Slovakia in 1974 and Ph.D. degree in Cybernetics from Technical University of Košice, Slovakia in 1995. He is a professor of the Department of Applied Mechanics and Mechatronics at the Faculty of Mechanical Engineering at the Technical University of Košice, Slovakia. He was a Fellow of the IEEE and the Institution of Engineering and Technology. His research interests include mechatronic systems, intelligent robotic systems, dust mass concentration measurement and measurement of non-electric quantities. He has authored more than 150 journal and conference papers on these topics.
\end{abstract}

Michal Kelemen, doc. Ing. PhD. He received M.S. degree in mechanical engineering from Technical University of Košice, Slovakia in 1998 and Ph.D. degree in Mechatronics from Technical University of Košice, Slovakia in 2002. He is an associated professor of the Department of Applied Mechanics and Mechatronics at the Faculty of Mechanical Engineering at the Technical University of Košice, Slovakia. He has been awarded the 1998 "Price of the VolksBank" for the best M.S. graduate and 2007 Price "Scientist of the year". His research interests include mechatronic systems, intelligent robotic systems, dust mass concentration measurement, measurement of non-electric quantities, and microcomputer systems. He has authored more than 180 journal and conference papers on these topics.

Ivan Virgala, Ing. PhD. He received M.Sc. degree in Mechatronics from Technical University of Košice, Slovakia in 2009 and PhD. degree in Mechatronics from Technical University of Košice, Slovakia in 2012. He is a researcher in Department of Applied Mechanics and Mechatronics at Faculty of Mechanical Engineering at Technical University of Košice, Slovakia. He has been awarded by "medal of dean" for excellent study. He is an editorial board member of 3 foreign scientific journals. His research field is design, modeling and control of manipulators, mobile robots, snake robots, humanoid robots and embedded systems. He has authored more than 50 journal and conference papers on these topics.

Lubica Miková, Ing. PhD. She received M.S. degree in mechatronics from Technical University of Košice in 2007 and Ph.D. degree in Mechatronics from Technical University of Košice, Slovakia in 2011. She is a researcher of the Department of Applied Mechanics and Mechatronics at the Faculty of Mechanical Engineering at the Technical University of Košice, Slovakia. Her research interests include mechatronics systems and robotics. She has authored more than 45 journal and conference papers on these topics.

Abstract: The paper deals with four legged walking robot Youpy. The robot has been designed as educational model. It has 8 degree of freedom in legs. Control of locomotion is based on reposition of centre of gravity. Standard servomechanism is used as actuator, which is frequently used for radio controlled models. After the simulations realized on 3D model, the functional model has been constructed. Designed flowchart of the forward locomotion has been verified on functional model. Maximum velocity for forward locomotion is $25 \mathrm{~cm} / \mathrm{s}$. Next part of the paper deals with conception of the feedback control of legs motion. 
Keywords: Robot, legged locomotion, sensor, mechatronics.

\section{Introduction}

Industrial robots have growing up potential in traditional and new areas of application with known operational conditions. Industrial robots usually work in structured environment, where every object has exactly defined position or trajectory.

Service robots have been developed together with industrial robots, but service robots work very often in unknown condition or working conditions may be dynamically changed. The area of their application is very large - machinery industry, electrical industry (assembly, disassembly, technology operations), nuclear industry (manipulation tasks etc.), health service (endoscopy, operation steps etc.), building industry (reconstruction, demolition, manipulation tasks etc.) tactical purposes (spying, exploration, navigation, military tasks, mine detection, bomb-disposing, fight against terrorists, rescue works), works in dangerous conditions (monitoring, diagnostic, cleaning, manipulation, repairing etc.).

Robot "Youpy" belongs into group of legged mobile service robots. It uses four legs. Design of the robot is coming from biological inspiration from the four legged animals. These legs consist of two plane joint coupling. Every leg is actuated and driven independently, so robot has very good assumptions for rough terrain locomotion. The paper deals with development and design of the robot. This robot is designed as didactic educational tool for practically oriented exercises in study program - mechatronics $[1,2,3]$.

The robot design is perfect way how the student can training in real situation. Student is confronted with many real problems and solving of them help to achieve experiences and skills. Several problems from mechanics, electronics and computer control can be demonstrated and the main task is to put the student into heuristic solving of the real problems and system thinking.

\section{Locomotion Principle}

The main task of the robot is to locomote on rough terrain for fulfillment of the manipulation tasks etc. Design of the robot comes from the arrangement, which is shown on Kinematic scheme on Fig. 1. The parallelogram mechanism has been used for legs kinematics. The parallelograms have a several advantages. The arrangement of the leg is shown on figure 2 .
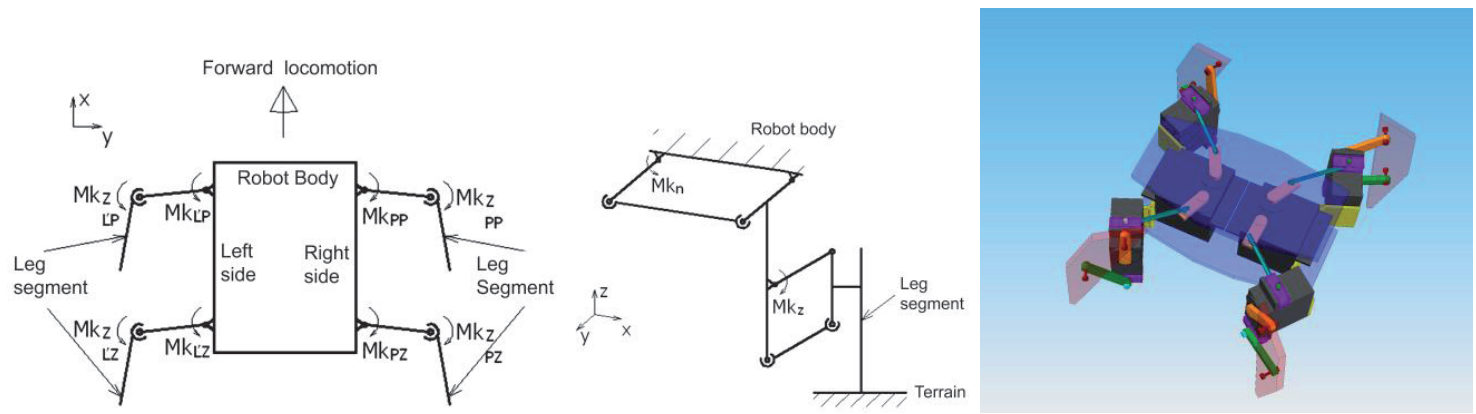

Fig. 1: Kinematic scheme of the legs arrangement Youpy robot (left) and kinematic scheme of the leg arrangement (right).

\section{Arrangement of the robot}

Servomechanism GWS S03 has been selected as actuator on the base of the analysis. It is shown on figure 2. It has maximal torque $0,24 \mathrm{Nm}$ and rotation velocity $43 \mathrm{rpm}$. The servomechanism is very often used in RC models for mechanism positioning. Desired value of rotation is defined via pulse width modulation signal. Rotation span is 180 degree. The cage (shown on figure 3 left) consists of two base plates which hold hip joint actuators via distance bars.

Hip joint is placed between the cases of actuators dedicated for actuating of the hip and knee joints (Fig. 3 left). Torque of the hip joint actuator is transferred via lever mechanism (Fig. 3 middle).

Knee joint is designed as parallelogram mechanism (Fig. 3 right). Overall robot design is shown on figure 4 (left). 3D model has been used for simulating of the motion trajectory of the joints. Joint positions with interferences have been verified. 

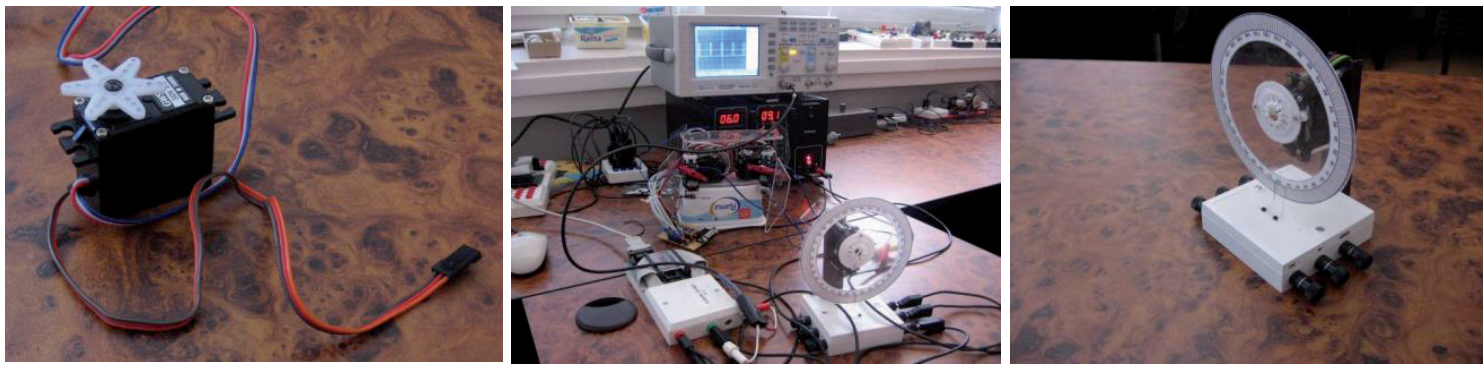

Fig. 2: Position servomechanism of the robot and position servomechanism of the robot.
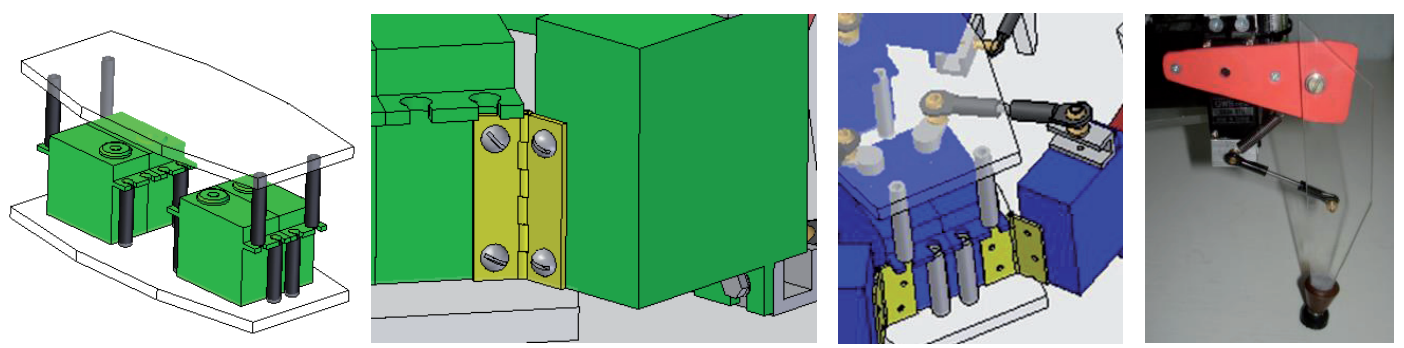

Fig. 3: Position servomechanism of the robot and position servomechanism of the robot.

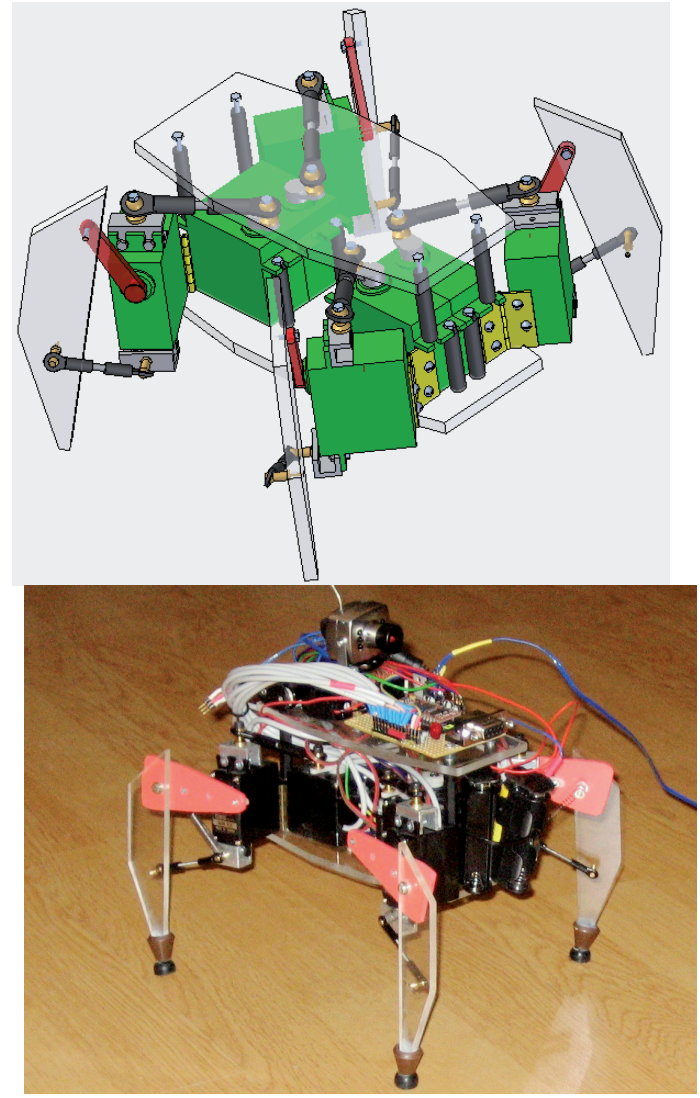

Fig. 4: Arrangement of the mechanisms and actuators of the robot (up) and functional model of the robot Youpy (down).
The designed robot has been realized as experimental functional model, which is shown on figure 4 (right). This model is controlled via wires with microcontroller Basic Stamp placed besides the robot. This model has been also used for experiments with joint arrangements. The experimental model has no feedback for controlling of joint rotations. Next developments have been oriented to feedback controlling of the joint rotations.

\section{Robot Locomotion}

Controlling of the four legged robot is more complicated then six legged robots. Four legged robot is not so stabile as more legged robots. Basic principle of the four legged locomotion is lies on moving of the robot centre of gravity for stability maintenance. Robot has to stay on three legs in every locomotion position. Centre of the gravity has to be inside the triangle defined with these three legs, which are in contact with terrain. Situation is more complicated when terrain is rough and inclined. Example of the forward locomotion sequence is shown on figure 5 .

Robot legs have been labeled (figure 6). Working positions of the legs have been defined (fig. 7 left). Figure 7 (right) shows flowchart for forward locomotion. Similar flowchart is also defined for backward locomotion and rotation of the robot. 


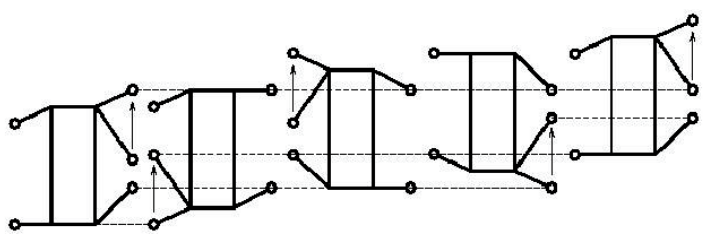

Fig. 5: Motion sequence for forward robot locomotion.

Experimental robot model has been controlled with Basic Stamp. Basic Stamp is able to execute 4000 instructions per second and it has only digital inputs and outputs. Stamp is able to compute only with integer numbers.

Next developments showed that Basic Stamp controller has been replaced with Basic Atom. Basic Atom is bale to execute 100.000 instructions per second and it has also eight analogue inputs with 10 bit built-in AD converters. Atom is able to compute with real number in floating point math mode. Another advantage of the Atom is hardware servo control system, which is able to control up to 32 actuators on the background of the main program executing. It allows joining analogue signals from joint position sensors.
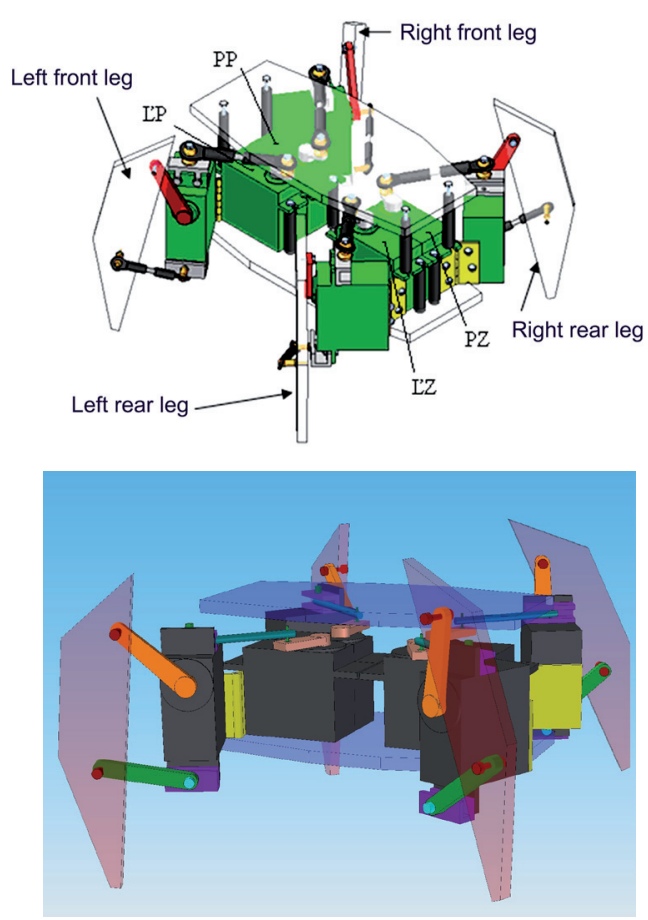

Fig. 6: Labels of the robot legs (left) and working positions of the robot legs (right).
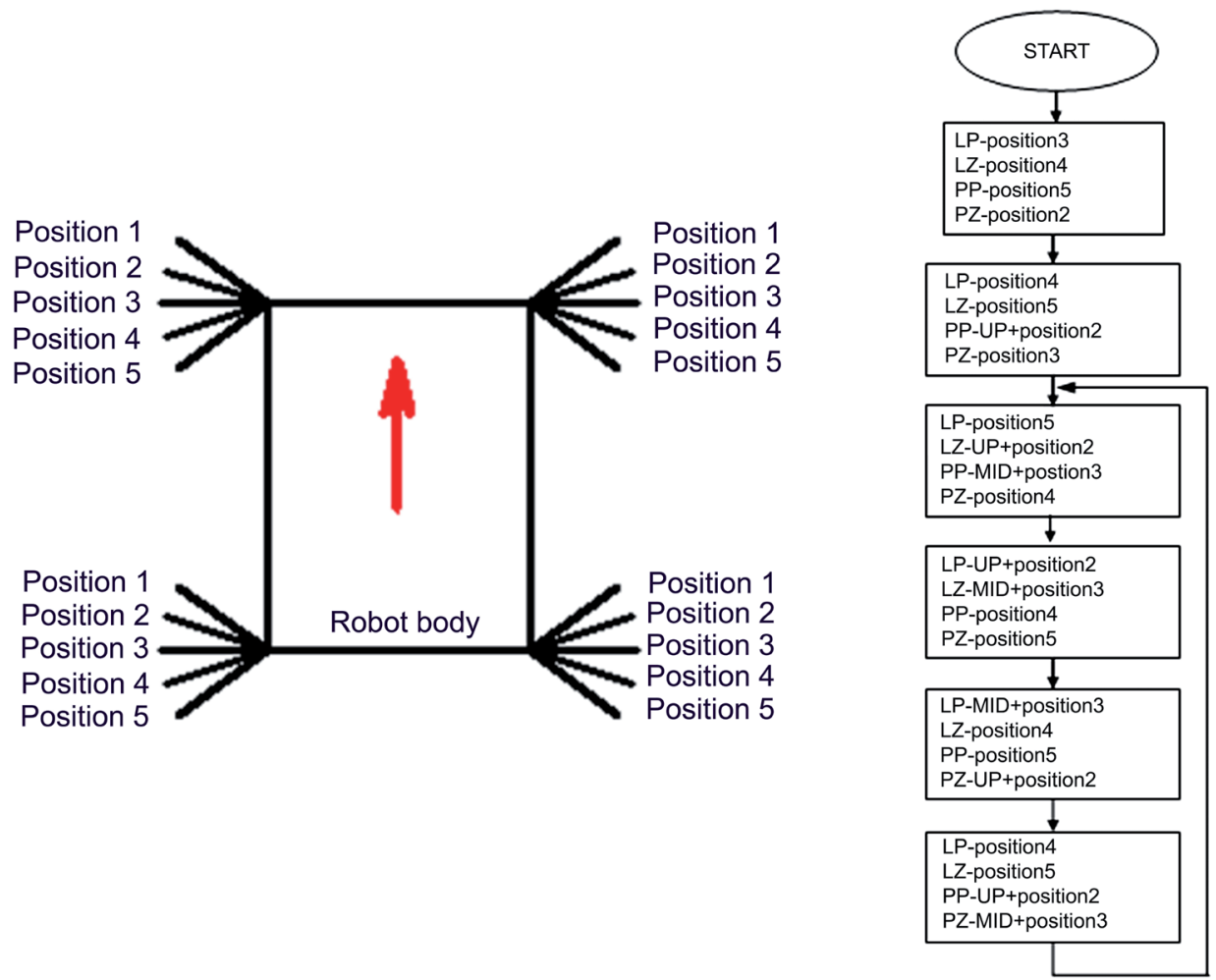

Fig. 7: Flowchart of the robot forward locomotion. 
Next problem was with sensing of the joint angle rotation. Potential application of the angle rotation sensor causes next complications and enlarging of the robot weight. So the internal sensors of the actuators have been used. Used actuators have own sensors for controlling. These signals from internal sensors have been attach to Basic Atom analogue inputs.

Now used microcontroller has information about actual position of the legs. Next step is to attach sensor of the inclination and after that Basic Atom will be able to math desired rotation of the leg joints. Joints loading change if inclination changes. Consequently, it is very important to do feedback control of joints rotation.

Robot has also own power supply from accumulator integrated into robot body. So it is now as autonomous robot. Maximum locomotion velocity has been $0,025 \mathrm{~m} / \mathrm{s}$ on the desk surface. There is a possibility to improve this velocity via optimalization of the locomotion algorithms. Robot also contains wireless camera module. After integration of the wireless controlling it can be used as robotic system controlled via teleoperator. Actual state of the robot Youpy is shown on figure 8. Robot has dimension $150 \mathrm{~mm}$ (long) and $170 \mathrm{~mm}$ (wide) and $100 \mathrm{~mm}$ (high).

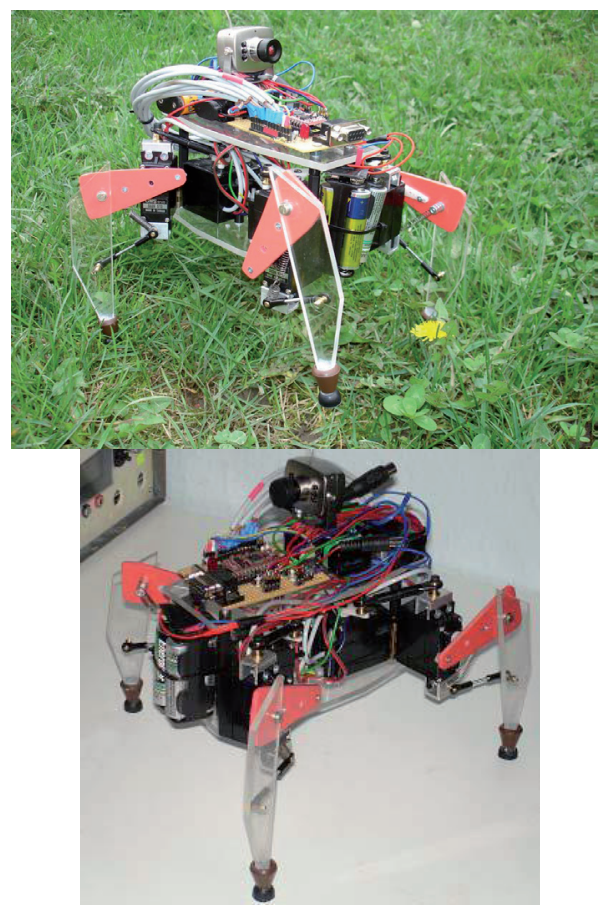

Fig. 8: Actual state of the robot Youpy.

\section{Conclusion}

The robot Youpy has been developed as didactic model for students training at the Faculty of Mechanical Engineering at the Technical University of Košice. The robot has eight degree of freedom. So it is complicated to control for achieving locomotion. It is able to overcome rough terrain against the wheeled robots. But it has higher power consumptions, because the actuators are still in start up and breaking mode [4-16].

\section{Acknowledgments}

The authors would like to thank to Slovak Grant Agency - project KEGA 048TUKE-4/2014, VEGA $1 / 1205 / 12$. Paper is the result of the Project implementation: University Science Park TECHNICOM for Innovation Applications Supported by Knowledge Technology, ITMS: 26220220182, supported by the Research \& Development Operational Programme funded by the ERDF.

\section{References}

[1] Jurisica, L., et al. (2005): Robotics. Slovak Technical University, Fac. of Elec. Eng., Bratislava, 2005. 134 pages.

[2] Kacir, K. (2011): Design of functional three wheel vehicle with navigation in unknown environment. Ms Thesis, Technical university of Kosice, Fac. of Mech. Eng., 2011, Kosice, 62 pages.

[3] Mikova, L., Trebuňa, F.: The Application of Simulation Methods for Modeling Mechatronic Systems. Acta Mechanica Slovaca. Vol. 16, No. 2, 2012, pp. 32-37. ISSN 1335-2393.

[4] Nitulescu, M.: Experiments in Mobile Robot Control. Mechatronics 2008. Paper \#200. Available online. 2008) Cited 0407-2013. http://www.mecatronica.pub.ro/romar/articole/ mecatronics2008_200.pdf.

[5] Vitko, A., Jurišica, L., Babinec, A., Duchoň, F., Klúčik, M.: Some Didactic Aspects of Teaching Robotics. In: AT\&P Journal Plus. ISSN 1336-5010. No. 2. Robotics in education (2010), pp. 109-112.

[6] Ivančo, V., Dovica, M., Gorzás, M.: In-Pipe Machine and Principles of its Motion and Control. Acta Mechanica Slovaca. Vol. 14. No. 2., 2010. pp. 66-70. ISSN 1335-2393.

[7] Dekan, M., Duchoň, F., Jurišica, L., Vitko, A., Babinec, A., iRobot Create Used in Education. In: Journal of Mechanics Engineering and Automation. ISSN 2159-5275. Vol. 3, Iss. 4 (2013), s. 197-202

[8] Koniar, D., Hargaš, L., Hrianka, M.: Application of standard DICOM in LabVIEW. Proc. of 7th conf. Trends in Biomedical Engineering, Kladno 11. - 13. 9. 2007 ISBN 978-80-01-03777-5. 2007. 
[9] Hargaš, L., Hrianka, M., Koniar, D., Izák, P.: Quality Assessment SMT Technology by Virtual Instrumentation. Applied Electronics 2007, Pilsen, 5. - 6. 9. 2007, ISBN 987-80-7043-537-3, 2007.

[10] Gmiterko, A., Virgala, I., Vacková, M.: Dynamic Analysis of Two-Mass System to Imitate Rectilinear Motion of a Snake. Acta Mechanica Slovaca. Vol. 14. No. 2. pp. 74-81. ISSN 13352393.

[11] Duchoň, F., Dekan, M., Jurišica, L., Vitko, A.: Some Applications of Laser Rangefinder in Mobile Robotics. In: Journal of Control Engineering and Applied Informatics. - ISSN 14548658. - Vol. 14, No. 2 (2012), s. 50-57

[12] Gmiterko, A., Kelemen, M., Kelemenová, T., Miková, L.: Adaptable Mechatronic Locomotion System. Acta Mechanica Slovaca. Vol. 14. No. 2. 2010. pp. 102-108. ISSN 1335-2393.

[13] Trebuňa, F., Šimčák, F., Handbook of experimental mechanics. 1st edition. Košice : TU of Kosice, Fac. Of Mech. Eng. 2007. 1526 pages. ISBN 970-80-8073-816-7.

[14] Hanzel, J., Duchoň, F., Rodina, J., Pásztó, P.: Global Navigation Systems for Mobile Robots. In: International Journal of Systems Applications, Engineering \& Development. - ISSN 2074-1308. - Vol. 7, Iss. 5 (2013), s. 279-285.

[15] Tölgyessy, Michael - Chovanec, L’uboš - Pásztó, Peter - Hubinský, Peter: A Plane Based Real-Time Algorithm for Controlling a Semi-Autonomous Robot with Hand Gestures Using the Kinect. In: International Journal of Imaging and Robotics. - ISSN 2231-525X. - Vol. 13, Iss. 2 (2014), s. 126-133.

[16] V. Baláž, , E. Ostertagová, D. Palaščáková. Using of e-learning for teaching extension at KVTaR Acta Mechanica Slovaca. Vol.. 10, No. 2-A (2006), pp. 47-50. - ISSN

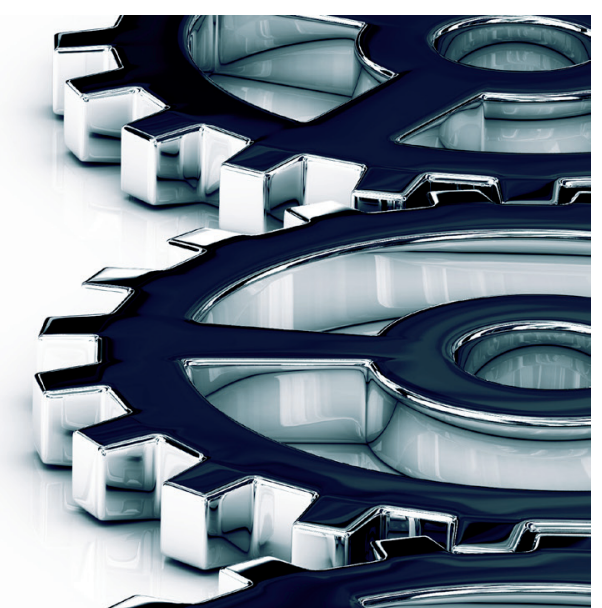
.

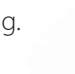

